\title{
Limitações do gerenciamento dos resíduos sólidos urbanos em município de pequeno porte
}

\begin{abstract}
A problemática envolvendo os resíduos sólidos é um dos problemas que a administração pública enfrenta, uma vez que o gerenciamento inadequado gera impactos negativos tanto econômicos, quanto ambientais e sociais. Assim, o objetivo do estudo consistiu em diagnosticar e propor diretrizes para o gerenciamento dos resíduos sólidos urbanos (RSU) do município de Matelândia/PR. Para tanto, realizou-se um levantamento quali-quantitativo dos RSU gerados no município por meio da determinação da composição gravimétrica dos resíduos destinados ao aterro sanitário municipal, foram obtidos dados de geração per capita diária e densidade dos resíduos; análise das condições ambientais da destinação adotada, conforme a avaliação de aterros de resíduos e condições das cooperativas de catadores, índice da qualidade dos resíduos (IQR) e índice de coleta seletiva (ICS), respectivamente. Os dados foram coletados in loco e aterros de resíduos e condições das cooperativas de catadores, índice da qualidade dos resíduos (IQR) e índice de coleta seletiva (ICS), respectivamente. Os dados foram coletados in loco e
análise da percepção ambiental dos munícipes desenvolvida com base na aplicação de entrevistas e elaboraçãa de mapas temáticos gerados conforme as respostas obtidas. Os resultados mostraram que são dispostos, em média, 2,9 toneladas de resíduos no aterro sanitário, sendo que, $31 \%$ são resíduos orgânicos, $24 \%$ rejeitos, $18 \%$ outros, $9 \%$ plásticos, $8 \%$ papel e papelão $4 \%$ metal e $1 \%$ vidro. A densidade dos resíduos foi calculada em $128 \mathrm{~kg}$.m-3 e a geração per capita em $672 \mathrm{~kg}$.dia-1. O IQR obtido foi de 5,0 e o ICS foi de 4,2, classificando as condições de operação como inadequadas, dentro das suas relativas faixas de classificação. Ao todo, foram entrevistadas 542 residências, destas, $66 \%$ afirmaram não saber a destinação final dada aos RSU, $22 \%$ indicaram o aterro sanitário e $12 \%$ o lixão. A regulamentação do cronograma da coleta convencional e seletiva, adequação da infraestrutura operacional do aterro sanitário e melhoria nas condicões de trabalho dos associados da cooperativa de catadores foram as proposições estabelecidas de acordo com o diagnóstico. As informações levantadas dos RSU fornecem ao gestor público não apenas o volume de resíduos gerados, mas, um panorama do manejo que abrange desde a geração (nas residências) até a destinação final (aterro e associação de reciclagem). A partir dos aspectos, sejam estes positivos ou negativos, o gestor público tem suporte para realizar o planejamento de ações corretivas e/ou preventivas.
\end{abstract}

Palavras-chave: Administração Pública; Diagnóstico; Composição Gravimétrica; Condições Ambientais; Percepção Ambiental.

\section{Limitations of urban solid waste management in small municipalities}

The problem that involves the solid waste is one of the problems that the public administration lives, the inadequate management generates not only a negative economic but also environmental and social impacts. In this way the objective of the study was to diagnose and propose guidelines for the management of urban solid waste (MSW) in the Matelândia city / PR. However, a qualitative-quantitative survey of MSW generated in the city was carried out by determining the gravimetric composition of the waste destined to the landfill from the city, the datas were obtained of daily per capita generation and density of residues; the analysis of the environmental conditions of the destination adopted, according to the evaluation of waste landfills and conditions of the waste collector cooperatives, waste quality index (IQR) and selective collection index (ICS), respectively. The data were collected in loco and analysis of the environmental perception of the residents developed based on the application of interviews and elaboration of thematic maps generated according to the answers obtained. The results showed that an average of 2.9 tons of waste is disposed in the landfill, $31 \%$ of which are organic waste, $24 \%$ waste, $18 \%$ others, $9 \%$ plastics, $8 \%$ paper and cardboard, $4 \%$ metal and $1 \%$ glass. The density of the waste was calculated at $128 \mathrm{~kg} . \mathrm{m}-3$ and the per capita generation at $672 \mathrm{~kg}$.dia-1. The obtained IQR was 5.0 and the ICS was 4.2 , classifying the operating conditions as inadequate, within their relative classification ranges. In all, 542 households were interviewed, of which $66 \%$ said they didn't know the final destination given to MSW, $22 \%$ indicated the landfill and $12 \%$ reported the landfill. The regulation of the schedule in the conventional and selective collection, adequacy of the operational infrastructure of the landfill and improvement landfill and $12 \%$ reported the landfill. The regulation of the schedule in the conventional and selective collection, adequacy of the operational infrastructure of the landfill and improvement
in the working conditions of the members' collectors' cooperative were the propositions established according to the diagnosis. The information collected from the USW provides the public manager with not only the volume of waste generated but also an overview of the management that covers everything from generation (residences) to disposal (landfill and recycling association). From the aspects, they can be positive or negative; the public manager is supported to carry out the planning of corrective and / or preventive actions.

Keywords: Public Administration; Diagnosis; Gravimetric Composition; Environmental Conditions; Environmental Perception.

Topic: Planejamento Urbano

Reviewed anonymously in the process of blind peer.
Received: 14/12/2017

Approved: 24/01/2018
Ana Paula Leite (D)

Universidade Tecnológica Federal do Paraná, Brasil

http://lattes.cnpq.br/7393012487016029

http://orcid.org/0000-0002-3148-3856

anapleite1@gmail.com

Thaís Helena Leite Nogueira (DD

Universidade Tecnológica Federal do Paraná, Brasil

http://lattes.cnpq.br/5943882561516029

http://orcid.org/0000-0003-2717-7386

thais helenas@live.com

\section{Thiago Edwiges (iD)}

Universidade Tecnológica Federal do Paraná, Brasil

http://lattes.cnpq.br/7643832070860943

http://orcid.org/0000-0002-6691-8100

thiago.edwiges@gmail.com

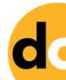

DOI: $10.6008 / C B P C 2179-6858.2018 .002 .0030$

\author{
Angela Laufer Rech (iD \\ Faculdade Educacional de Medianeira, Brasil \\ http://lattes.cnpq.br/2336631329251833 \\ http://orcid.org/0000-0001-6103-7825 \\ angelalaufer@yahoo.com.br
}

\section{Referencing this:}

LEITE, A. P.; NOGUEIRA, T. H. L.; EDWIGES, T.; RECH, A. L.. Limitações do gerenciamento dos resíduos sólidos urbanos em município de pequeno porte. Revista Ibero Americana de Ciências Ambientais, v.9, n.2, p.382-396, 2018. DOI: http://doi.org/10.6008/CBPC21796858.2018 .002 .0030 


\section{INTRODUÇÃO}

Os resíduos sólidos são definidos, de acordo com a norma NBR 10.004/2004 como resíduos nos estados sólido e semissólido, que resultam de atividades de origem industrial, doméstica, hospitalar, comercial, agrícola, de serviços e de varrição. A classificação dos resíduos apresenta a legislação brasileira, Política Nacional dos Resíduos Sólidos (PNRS), Lei 12.305/2010, de acordo com sua origem é subdividida em: resíduos domiciliares, resíduos de limpeza urbana, resíduos sólidos urbanos, resíduos de estabelecimentos comerciais e prestadores de serviços, resíduos dos serviços públicos de saneamento básico, resíduos industriais, resíduos de serviços de saúde, resíduos da construção civil, resíduos agrossilvopastoris, resíduos de serviços de transportes e resíduos de mineração. Logo, os resíduos sólidos urbanos (RSU) é o agrupamento dos resíduos domiciliares, de limpeza urbana e produzidos por pequenos geradores.

Quanto à geração de RSU, o Plano Nacional de Resíduos Sólidos (BRASIL, 2012) apresenta uma estimativa da composição gravimétrica (Figura 1a), sendo que 50\% é referente ao material orgânico. Segundo Abramovay et al. (2013), o crescimento econômico de um país traduz-se por um declínio na participação relativa dos resíduos orgânicos e aumento de produtos recicláveis na composição dos resíduos, assim como se pode visualizar na Figura 1 (b) e (c), em que em países de baixa renda os orgânicos chegam a $64 \%$ do total dos resíduos, proporção que cai para $28 \%$ nas nações mais ricas.

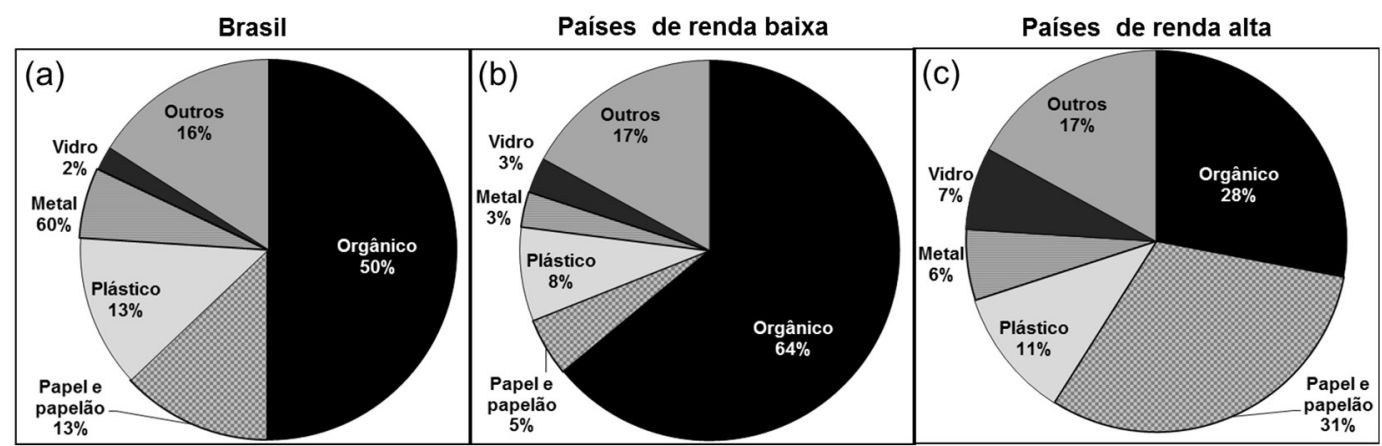

Figura 1: Composição gravimétrica média dos resíduos sólidos no Brasil (a) em países de renda baixa (b) e países de renda alta (c). Fonte: Abramovay et al. (2013).

Assim, de acordo com Barreto et al. (2015), a análise da composição dos RSU torna-se ferramenta de gestão, auxiliando na tomada de decisão, implicando em estratégias para redução dos custos da coleta, destinação e de disposição em aterro. A geração per capta (GPC) de resíduos sólidos é tida como a massa de resíduos gerada por um habitante no intervalo de um dia (CAMPOS, 2012). O Sistema Nacional de Informações sobre Saneamento (SNIS) estimou que a geração per capta de RSU em 2015 foi de 1,00 kg hab${ }^{1} \mathrm{dia}^{-1}$ (MINISTÉRIO DAS CIDADES, 2017).

Entretanto, como é possível se observar na Figura 2, a GPC do estado do Paraná se apresenta abaixo da média nacional. Tal fato pode ser explicado por algumas hipóteses levantadas pelo SNIS, como a prática de pesagem rotineira dos resíduos, comum na região Sul e Sudeste e também a maior presença de aterros sanitários privados nessas regiões, apresentando maior rigor na seleção dos resíduos a serem destinados. Além da incidência de sub-registros de quantidades coletadas por coleta seletiva 'não-oficial', influenciando nesse valor. O levantamento do Ministério das Cidades (2017) traz à luz as regiões Norte e Nordeste com a 
GPC mais elevada, devido à característica da composição gravimétrica em tais localidades, com maiores proporções de matéria orgânica do que as demais regiões.

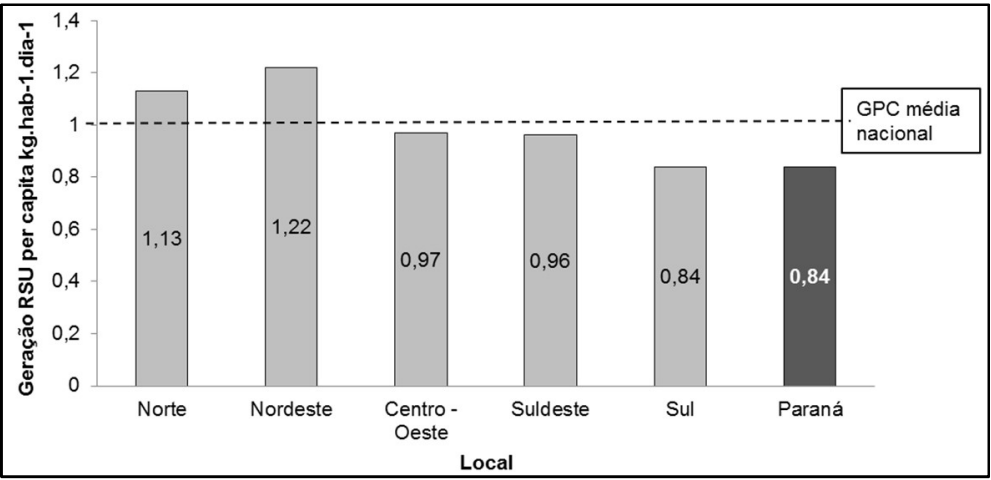

Figura 2: Geração per capita de RSU por região. Fonte: Ministério das Cidades (2017).

Para Ussier et al. (2014), a GPC torna-se um fundamental instrumento de gerenciamento de resíduos sólidos para os municípios. "A geração dos resíduos domiciliares varia de acordo com o porte dos municípios e regiões geográficas do país, em função do vigor da atividade econômica e tamanho e renda da população" (BRASIL, 2012). Como se pode perceber na Tabela 1.

Tabela 1: Massa coletada per capita por porte do município.

\begin{tabular}{|l|l|}
\hline População urbana (habitantes) & RSU (kg.habitante-1dia-1) \\
\hline Até 30 mil & 0,85 \\
\hline De 30.001 a 100.000 & 0,90 \\
\hline De 100.001 a 250.000 & 0,90 \\
\hline De 250.001 a 1.000 .000 & 0,96 \\
\hline De 1.000 .001 a 3.000 .000 & 1,29 \\
\hline Acima de 3.000 .001 & 1,12 \\
\hline
\end{tabular}

Fonte: Brasil (2013).

Para a gestão e gerenciamento dos resíduos devem-se considerar as diretrizes aplicáveis estabelecidas pela Política Nacional de Resíduos Sólidos, para tanto, deve ser observada a seguinte hierarquia das ações de manejo: não geração, redução, reutilização, reciclagem, tratamento dos resíduos sólidos e disposição final ambientalmente adequada dos rejeitos.

A PNRS define disposição final ambientalmente adequada como sendo: "Distribuição ordenada de rejeitos em aterros, observando normas operacionais específicas de modo a evitar danos ou riscos à saúde pública e à segurança e a minimizar os impactos ambientais adversos" (BRASIL, 2012). Sendo que, os rejeitos são os resíduos sólidos que, depois de esgotadas todas as possibilidades de recuperação, não apresentem outra possibilidade que não a disposição final ambientalmente adequada.

A disposição final de RSU no Brasil é irregular em 41,3\% dos municípios (ABRELPE, 2015). Ou seja, a maior parte destes adota uma destinação final inadequada frente à PNRS (aterros controlados e lixões), assim como se pode perceber na Figura 3, na qual se percebe ainda que apenas na Região Sul o cenário é favorável, com 59\% dos municípios utilizando-se de aterros sanitários. 


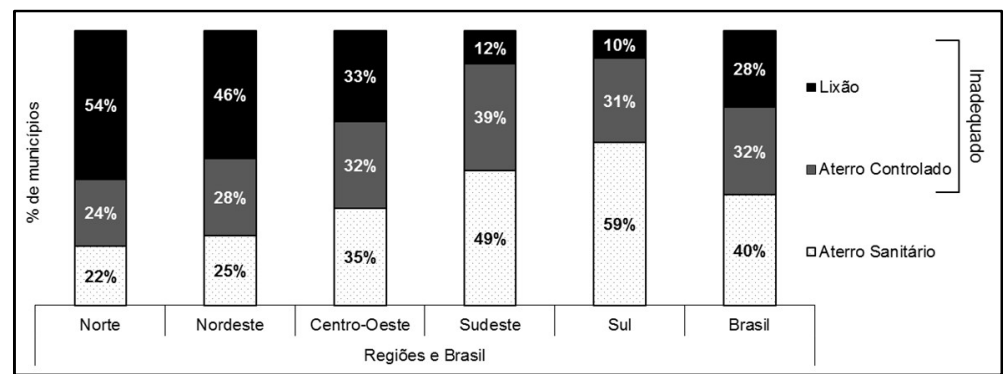

Figura 3: Porcentagem de municípios por tipo de disposição final adotada Fonte: ABRELPE (2015).

A ABNT define aterro sanitário como sendo uma técnica de disposição de resíduos sólidos urbanos no solo, sem causar danos à saúde pública e à sua segurança, minimizando os impactos ambientais. Os impactos gerados decorrentes da má gestão e gerenciamento dos resíduos sólidos geram problemas sociais, econômicos e ambientais. Quanto aos RSU, a escassez de recursos técnicos municipais voltados para a destinação e disposição final adequada e falta de qualificação dos responsáveis pelo gerenciamento é uma situação comum, principalmente em municípios de pequeno porte.

Deste modo o objetivo da presente pesquisa consistiu em diagnosticar e propor diretrizes para o gerenciamento dos Resíduos Sólidos Urbanos do município de Matelândia, Paraná. Para tanto, realizou-se um levantamento quali-quantitativo dos RSU gerados no município, análise das condições ambientais da destinação dos resíduos adotada e da percepção ambiental dos munícipes.

\section{METODOLOGIA}

Realizou-se o estudo em questão no município de Matelândia que pertence à Mesorregião Oeste do estado do Paraná, distante 560,90 km da capital, Curitiba (IPARDES, 2015). O município possui área territorial de $639.746 \mathrm{~km}^{2}$ e população de 16.078 habitantes, sendo que, destes, 11.613 residem na zona urbana. E por ter um número de munícipe inferior à 20.000, de acordo com Brasil (2005) é considerado de pequeno porte, como dinâmica social característica, índices de escolaridade e renda familiar baixos se comparados a municípios maiores, núcleos familiares bem definidos e habitações sendo principalmente casas (VIEIRA, 2011).

Os RSU do município de Matelândia são destinados ao aterro sanitário municipal e à ASCARMAT (Associação de Catadores de Materiais Recicláveis de Matelândia). Deste modo, para a elaboração do diagnóstico do gerenciamento dos RSU do município de Matelândia consistiu em três etapas: levantamento quali-quantitativo da geração de RSU; avaliação das condições ambientais das alternativas de destinação final dos mesmos (aterro sanitário municipal e ASCARMAT) e análise da percepção ambiental e conduta da população sobre o tema 'Resíduos Sólidos'. E com base nos dados levantados pode-se propor diretrizes para o gerenciamento.

\section{Levantamento Quali-quantitativo da Geração de Resíduos Sólidos Urbanos}

Para a determinação da composição gravimétrica dos RSU destinados ao aterro sanitário municipal de Matelândia, utilizou-se a metodologia do quarteamento, com adaptações no procedimento utilizado em 
estudo realizado por Costa et al. (2010). Segundo a ABNT (2004b), o quarteamento é um processo de divisão em quatro partes iguais de uma amostra pré-homogeneizada dos resíduos sólidos provenientes da coleta, sendo tomadas duas partes opostas entre si para constituir uma nova amostra e descartadas as partes restantes. Essa nova amostra é homogeneizada novamente e dividida em quatro partes iguais, descartando os dois quartis opostos. Assim, o processo de quarteamento é repetido até que se obtenha o volume desejado.

Para tanto, iniciou-se a coleta de quatro amostras de $200 \mathrm{~L}$ na pilha de resíduos sólidos descarregadas no aterro sanitário, sendo três na base e uma no topo, aplicou-se o procedimento de quarteamento sob uma Iona plástica, como ilustra as Figuras 4 e 5, até se obter o volume final desejado de 200 litros. Volume este que foi pesado e segregado em: orgânico, plástico, papel e papelão, metal, vidro, rejeitos e outros a fim de se determinar o percentual de cada classe em relação à massa total.

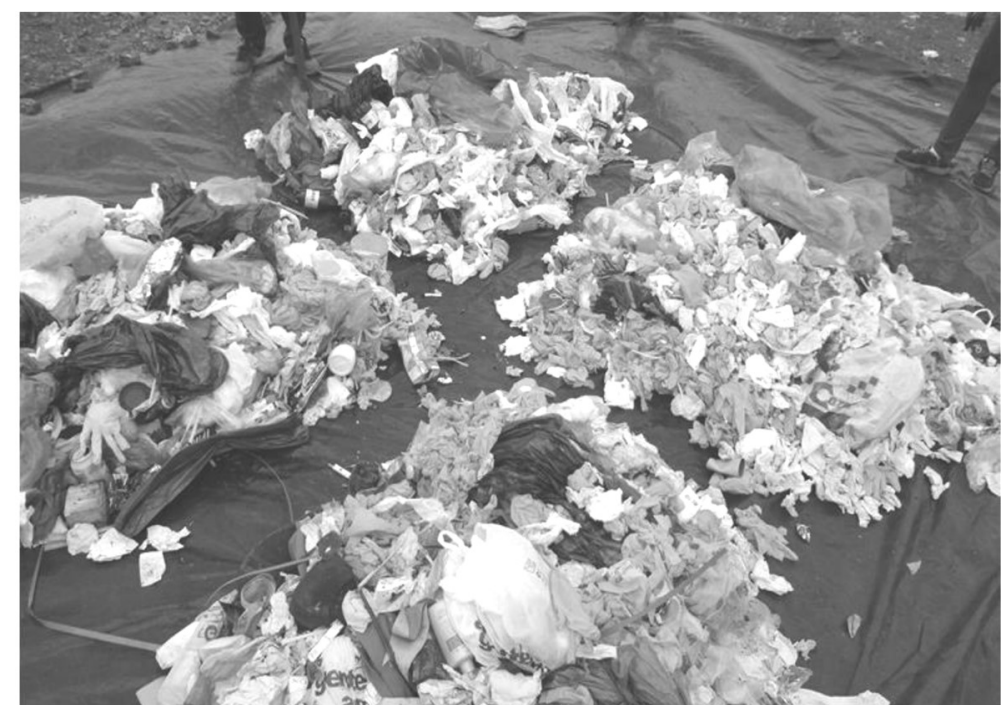

Figura 4: Homogeneização e partição da amostra de resíduos sólidos.

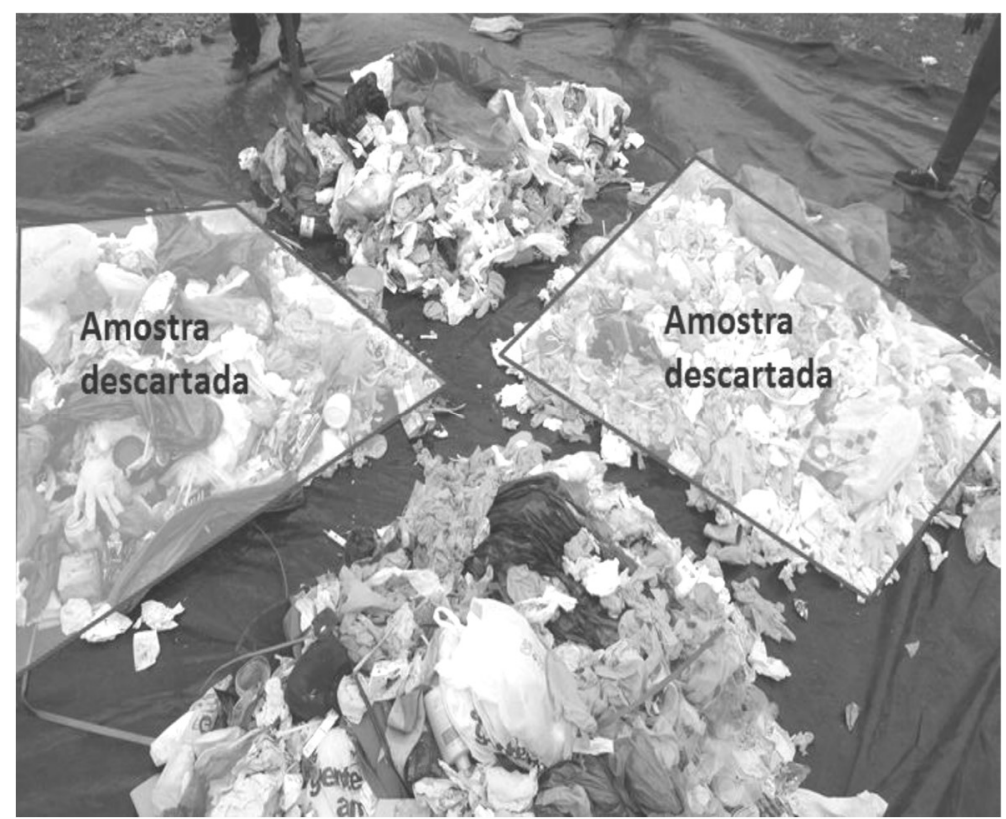

Figura 5: Descarte de porções opostas dos resíduos sólidos. 
Realizaram-se os quarteamentos durante cinco dias consecutivos de janeiro de 2015, a fim de se obter a geração média de resíduos, visto que a coleta de resíduos obedece a um cronograma semanal. Efetuou-se, portanto, o procedimento com todas as cargas descarregadas no aterro sanitário neste período, sendo que não ocorre coleta aos sábados e domingos, totalizando-se 10 quarteamentos (em média 2 cargas de resíduos diárias).

Para o cálculo da geração total de RSU no município obteve-se a massa total de resíduos disposta no aterro, além, por meio da densidade aparente calculada a partir da massa da amostra contida em $200 \mathrm{~L}$, amostra final do quarteamento. Entretanto, para a determinação total da geração dos RSU, caracterizou-se ainda os resíduos recicláveis destinados à ASCARMAT (Associação de Catadores de Materiais Recicláveis de Matelândia), já que, no Município ocorre a coleta seletiva, logo, nem todos os resíduos vão para o Aterro Sanitário. Desta forma, a quantificação se deu por meio de obtenção de dados secundários junto á ASCARMAT. Obteve-se a quantificação da Geração Per Capita Diária (GPCD) de RSU a partir da razão entra a massa diária de resíduos urbanos (destinadas ao aterro sanitário municipal e a ASCARMAT) pelo número total de habitantes atendidos pela coleta de resíduos municipal.

\section{Avaliação das Condições Ambientais das Alternativas de Destinação de RSU}

Para a avaliação das condições ambientais do aterro sanitário municipal de Matelândia foi utilizado a metodologia da Cetesb de avaliação de aterros de resíduos, IQR (CETESB, 2010). De modo geral, o IQR é dividido em tópicos, no qual, são atribuídos pesos, e no final é gerada uma nota. Esta nota classifica a condição do aterro em inadequada ou adequada. O IQR é o produto da aplicação de um questionário padronizado, que avalia as características locacionais, estruturais e operacionais dos locais de tratamento e disposição de resíduos. Os dados apurados permitem expressar as condições ambientais desses locais (CETESB, 2010).

Com finalidade semelhante ao IQR, o ICS aponta a condição das cooperativas de catadores, avaliando diversos fatores, tais como: infraestrutura, uso de EPI, equipamentos, entre outros. A nota obtida ao final do questionário, também elaborado pela Cetesb, classifica a coleta seletiva nos seguintes conceitos: inadequado; regular e adequado (CETESB, 2010). Sendo que, o levantamento de dados para o IQR e ICS se deu por meio de visitas a campo aos locais avaliados e questionamentos aos responsáveis.

\section{Análise da Percepção Ambiental}

A percepção ambiental dos munícipes em relação à temática resíduos sólidos foi fundamentado na aplicação de questionários fechados com perguntas voltadas à caracterização das residências entrevistadas (renda familiar e escolaridade do responsável pela residência), postura da população quanto ao serviço de coleta e percepção da população quanto ao conhecimento da destinação final dos resíduos urbanos. A metodologia utilizada baseou-se em uma pesquisa descritiva e explicativa. A pesquisa foi desenvolvida pelo método de levantamento de campo. Na qual, os questionários foram aplicados em amostras representativas 
de cada bairro. Para definir uma amostra representativa de cada bairro de Matelândia utilizou-se a equação de Gil (2008), para populações finitas (inferior a 100 mil membros), descrita abaixo:

$$
n=\frac{\delta^{2} p q N}{e^{2}(N-1)+\delta^{2} p q}
$$

Onde:

$\mathrm{n}$ = tamanho da amostra final, ou seja, a população a ser entrevistada em cada bairro;

$\delta^{2}=$ nível de confiança, sendo que utilizou-se um valor de $95 \%$, com isso $\delta^{2}$ é igual a 1,96 (tabelado); $\mathrm{N}=$ tamanho total da população, na ocorrência, as populações de cada bairro que pode ser visualizada na Tabela 1; $p=$ probabilidade de o fenômeno ocorrer; $q$ = probabilidade complementar, como os valores de $p$ e q não são conhecidos, usa-se atribuir o valor de 0,5 para o produto das duas variáveis, segundo Gil (2008); $\mathrm{e}=$ probabilidade de ocorrência de erro, assumiu-se para este caso um erro de $5 \%$.

Aplicaram-se os questionários pelo método da entrevista, no perímetro urbano do município de Matelândia, em cada bairro, passando de porta em porta, sendo as residências escolhidas de forma aleatória, até que o número de habitantes necessário fosse atingido. Para a análise dos dados, optou-se pela elaboração de mapas temáticos com os resultados dos questionários aplicados referentes à caracterização da população e percepção ambiental em cada bairro. Para a elaboração dos mapas temáticos, considerou-se sempre o pior cenário quanto à escolaridade, renda familiar e percepção ambiental sobre a disposição dos resíduos. Assim, a cada bairro atribuiu-se uma cor, de acordo com a resposta dos entrevistados, indicando: porcentagem da população de menor escolaridade, menor renda e que não sabe a disposição final dos RSU. Com base nos resultados do diagnóstico dos resíduos sólidos urbanos no município de Matelândia - Paraná realizou-se a proposição de diretrizes para o gerenciamento destes resíduos sólidos em relação à promoção da não geração, redução, reutilização e reciclagem.

\section{RESULTADOS E DISCUSSÃO}

\section{Geração de Resíduos Sólidos Urbanos}

De acordo com a Figura 6 (a) pode-se observar a média da massa de resíduos segregados por quarteamentos realizados no aterro sanitário municipal de Matelândia e, deste modo, tem-se distribuição geral das classes dos resíduos sólidos gerados no município de Matelândia, Figura 6 (b). Percebe-se ainda que a maior representatividade é dos resíduos orgânicos (31\%), seguidos dos rejeitos (24\%). O percentual de matéria orgânica disposta no aterro sanitário municipal (31\%), apesar de ser o mais representativo é inferior à média nacional de 50\% (BRASIL, 2012). Porém, visto que no município existe coleta seletiva, espera-se que a quantidade de resíduos orgânicos seja maior.

O percentual de resíduos sólidos recicláveis presentes na massa de resíduos disposta no aterro sanitário municipal, de acordo com a composição gravimétrica, é de $45,8 \%$, o que indica falhas no serviço de coleta e gestão dos resíduos sólidos, pois estes deveriam estar sendo destinados à reciclagem e/ou reaproveitamento. Sendo que, por meio do rompimento dos sacos de resíduos, pode-se perceber a entrada de resíduos recicláveis previamente segregados pela população e não segregados. E a categoria outros foi composta de: plástico metalizado, isopor, embalagens multicamadas, madeira e borracha principalmente. 


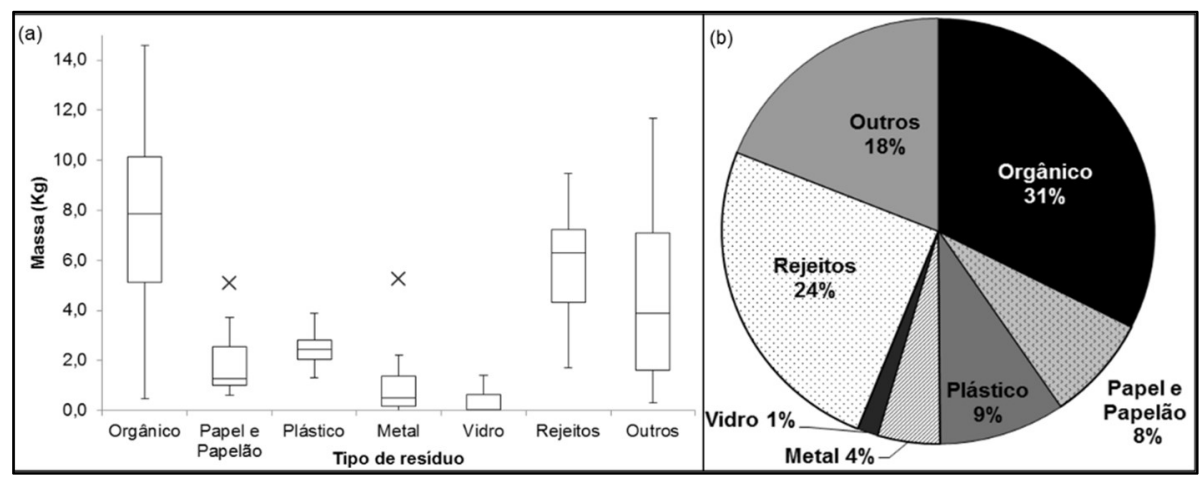

Figura 6: (a) Média da massa de cada tipo de resíduo segregado no quarteamento; (b) Composição gravimétrica dos resíduos dispostos no aterro sanitário municipal de Matelândia.

A porcentagem de rejeitos obtida pelo método do quarteamento foi de apenas $23,6 \%$. Entretanto, como já citado anteriormente, a PNRS estabelece que a disposição final em Aterro Sanitário é indicada apenas para os rejeitos, pois não há como reaproveitar ou reutilizar este tipo de resíduo. Assim, como base nos dados coletados, no Aterro Sanitário é disposta diariamente, uma média de 2,9 toneladas.

O peso específico dos resíduos sólidos dispostos no aterro sanitário municipal calculado foi obtido pela razão da massa de resíduos do quarteamento pelo volume final (200 L). Sendo que estes resíduos se apresentavam soltos, dada ao rompimento das sacolas e homogeneização, desta forma, pode-se comparar os valores de densidade obtidos com o peso específico médio nacional dos resíduos sólidos urbanos soltos, $250 \mathrm{~g} \mathrm{~m}^{-3}$

Assim, pode-se perceber que a densidade dos resíduos dispostos no aterro $\left(128 \mathrm{~kg} \mathrm{~m}^{-3}\right)$ apresentase abaixo do esperado, este fato se justifica dada a composição gravimétrica dos resíduos, na qual a porcentagem de matéria orgânica é inferior da média nacional, visto a presença de resíduos sólidos indevidos, cujo destino adequado não é o aterro sanitário. Quanto aos resíduos recicláveis destinados à ASCARMAT, segundo a associação, os principais materiais destinados à reciclagem são papelão, papel e plástico. Em média são recebidos 20.160 kg de recicláveis por mês, ou seja, $672 \mathrm{~g} \mathrm{dia}^{-1}$.

Tem-se, portanto uma estimativa da massa total de resíduos domiciliares gerados diariamente no município: $3.534 \mathrm{~kg}$. Considerando a população atendida pela coleta de resíduos, que segundo a Prefeitura Municipal é de 10.585 habitantes, pode-se obter a geração per capita de resíduos sólidos urbanos de 0,334 kg.hab ${ }^{-1} \mathrm{dia}^{-1}$. A geração per capta apresentou-se abaixo do esperado, devido à densidade média dos resíduos sólidos obtida ser inferior à média nacional.

\section{Condições Ambientais das Alternativas de Destinação de RSU}

Aplicando-se a pontuação e o cálculo do índice estabelecido pela CETESB (2010), quanto ao Índice de Qualidade de Resíduos - IQR (Tabela 2), o resultado obtido no aterro sanitário municipal de Matelândia é de 5,0 , classificando assim as condições do local como inadequadas.

Tabela 2: IQR Aterro sanitário municipal de Matelândia.

\begin{tabular}{|l|l|l|}
\hline Item & Pontuação máxima & Pontuação obtida \\
\hline Estrutura de apoio & 9 & 4 \\
\hline Frente de trabalho & 15 & 0 \\
\hline
\end{tabular}




\begin{tabular}{|l|l|l|}
\hline Taludes e bermas & 15 & 11 \\
\hline Superfície superior & 10 & 10 \\
\hline Estrutura de proteção ambiental & 42 & 22 \\
\hline Outras informações & 10 & 4 \\
\hline Característica da área & 4 & 4 \\
\hline
\end{tabular}

O IQR apontou os seguintes pontos a melhorar no Aterro Sanitário: a falta de balança e vigilante e a qualidade do acesso à frente de descarga de resíduos, a dimensão da frente de trabalho para os veículos realizarem o manejo dos resíduos, a falta de compactação e recobrimento diário dos resíduos, a existência de afloramento de chorume. Além disso, quesitos como disposição de resíduos temporariamente em locais sem drenagem, a inexistência de drenagem provisória das águas pluviais, monitoramento das águas subterrâneas e monitoramento geotécnico, a ocorrência de odores, presença de aves e animais e o recebimento de resíduos não autorizados corroboram para as condições inadequadas do Aterro Sanitário.

Sendo está uma situação preocupante, pois, pode-se inferir que o aterro sanitário municipal de Matelândia não opera nas condições previstas em seu licenciamento. Assim, o empreendimento opera nas formas de um aterro irregular, promovendo impactos ambientais. Quanto ao cálculo do Índice de Coleta Seletiva - ICS estabelecido pela CETESB (Tabela 3), o resultado obtido pela ASCARMAT foi de 4,2. Deste modo à classificação da coleta seletiva de Matelândia é inadequada.

Tabela 3: ICS da ASCARMAT.

\begin{tabular}{|l|l|l|}
\hline Item & Pontuação máxima & Pontuação obtida \\
\hline Quantidade de recicláveis comercializados & 10 & 10 \\
\hline Gestão & 20 & 20 \\
\hline Infraestrutura do centro de triagem & 23 & 13 \\
\hline Condições operacionais & 39 & 12 \\
\hline Educação ambiental & 24 & 12 \\
\hline
\end{tabular}

De acordo com tal avaliação os principais pontos a serem melhorados neste quesito são as condições de infraestrutura e condições operacionais da ASCARMAT, visto que, não há um sistema de separação como mesa ou esteira de triagem, tão pouco elevador de carga e não há preparação do local de recepção do material coletado. Quanto as condições operacionais a ASCARMAT não pontuou nenhum item relativo a higiene e segurança. Em sua maioria os EPI's não são utilizados devido aos seguintes fatores: os associados não utilizam uniforme; há geração de fortes odores; presença de vetores e animais.

De acordo com o resultado final do ICS pode-se confirmar que a associação de catadores não é operada nas condições mais adequadas, desta maneira, os possíveis benefícios de uma associação de catadores não podem ser observados de forma satisfatória no município. A reciclagem possui vantagens sociais, econômicas e ambientais que não são aproveitadas em seu potencial, pois as condições de trabalho dos associados não promovem a dignidades dos mesmos, os materiais provenientes da coleta seletiva por vezes acabam pendendo seu valor comercial e o acúmulo de resíduos na associação promovem diversos impactos ambientais. 


\section{Percepção Ambiental}

Utilizando-se a metodologia estabelecida por Gil (2008), calculando-se o plano amostral representativo de cada bairro, o número de residências entrevistadas foi de 542 somando-se todos os bairros da zona urbana do município de Matelândia. A maioria dos entrevistados informou receber entre 2 a 5 salários mínimos (Figura 7), o que representa que a maior parte dos habitantes do município possui renda de baixa e média. Tem-se ainda que $16 \%$ não informaram a renda.

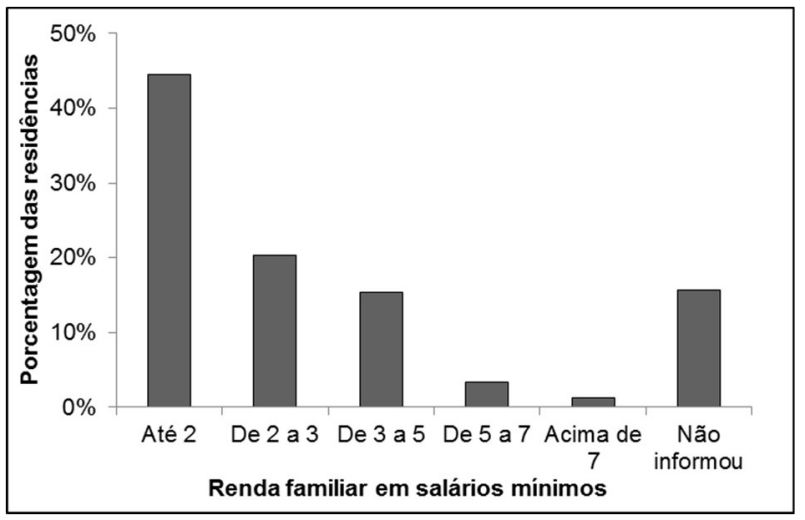

Figura 7: Variação da Renda Familiar no Município de Matelândia.

A distribuição espacial da renda familiar baseando-se apenas na população indicou menor renda consta na Figura 8. O bairro Jardim Primavera apresentou menor renda familiar, no qual $64,6 \%$ dos entrevistados indicou receber até dois salários mínimos. Destaca-se tal fato, visto que a reanda é um dos fatores que interferem nas características de geração de resíduos.

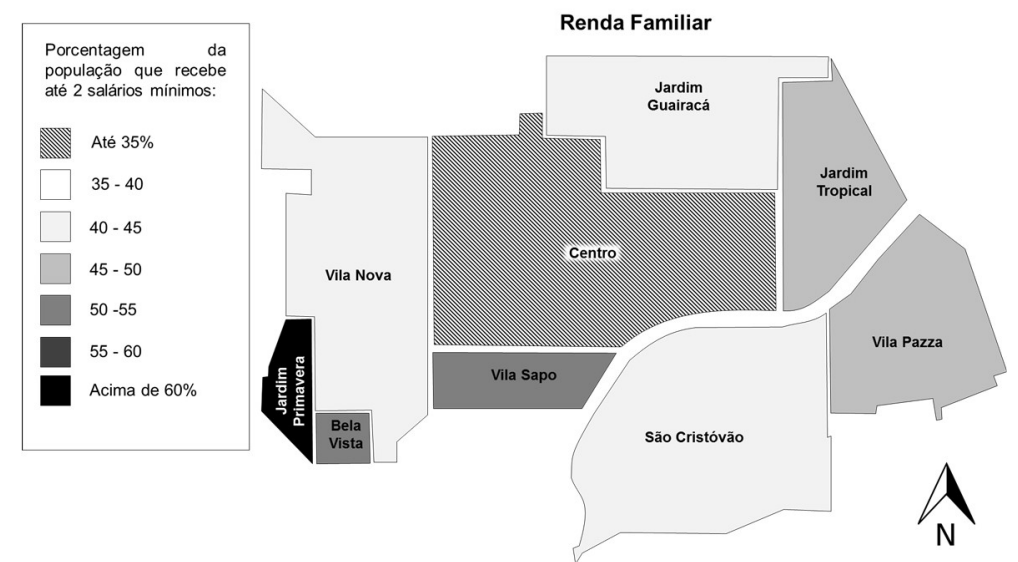

Figura 8: Distribuição espacial da renda familiar da população por bairros.

Quanto à escolaridade, de acordo com a Figura 9, tem-se que a maioria dos entrevistados, considerando toda a zona urbana do município, possui Ensino Médio Completo, cerca de $23 \%$. O nível de instrução de cada indivíduo influencia na percepção ambiental e a interação sociedade e o meio ambiente. Para Cruz et al. (2015), a maneira como cada indivíduo trata essa situação é determinante para produção de resíduos.

Considerando-se os entrevistados que indicaram que não possuem formação escolar destaca-se o bairro Vila Sapo (Figura 10), no qual, aproximadamente, $25 \%$ da população não possui escolaridade. Em 
contrapartida, no centro, $20 \%$ da população possui ensino superior completo. Assim, cada indivíduo percebe, reage e responde diferentemente frente às ações sobre o meio ambiente. As respostas ou manifestações são, portanto, resultado das percepções, dos processos cognitivos, julgamentos e expectativas de cada indivíduo (COSTA, 2013). Logo, o nível de escolaridade é um fator influenciador na percepção ambiental de uma determinada região. Desta forma, identificando-se a fração da população que indicou possuir escolaridade até o nível primário ou inferior, tem-se então a Figura 10, apresentando a distribuição espacial da escolaridade por bairros.

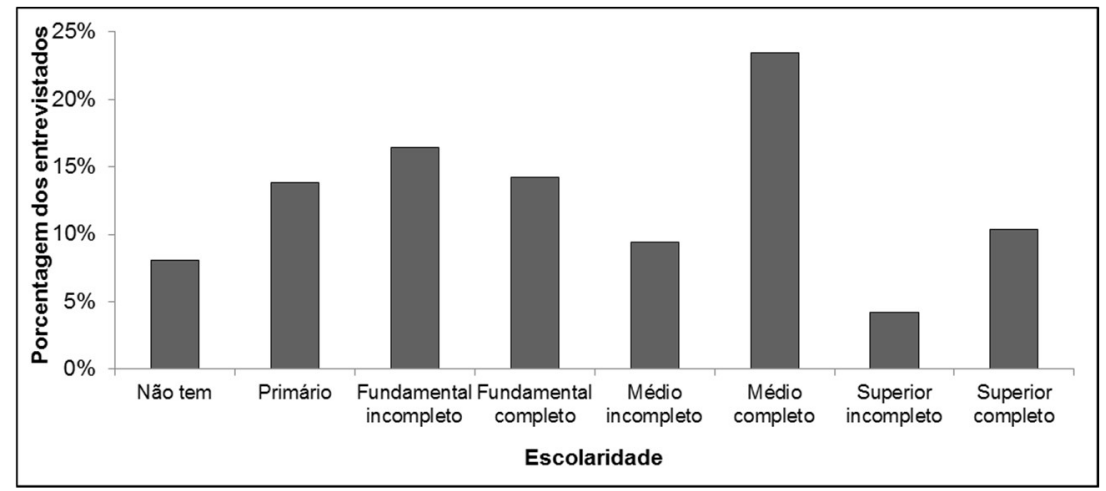

Figura 9: Variação da Escolaridade no Município de Matelândia.

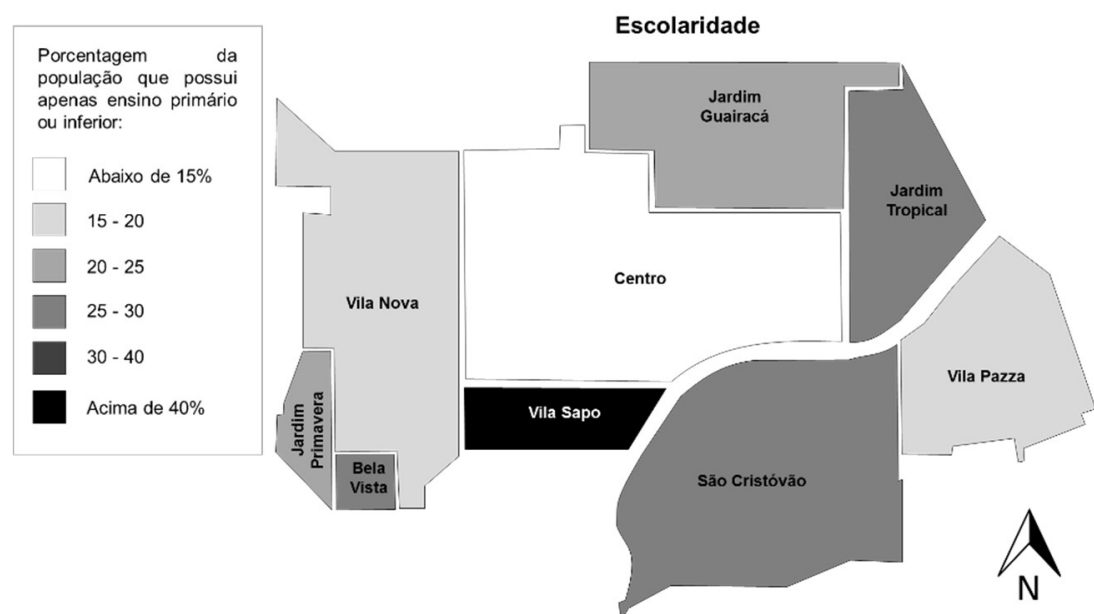

Figura 10: Distribuição espacial da escolaridade da população por bairros.

Os moradores foram questionados ainda quanto à coleta de resíduos sólidos e coleta seletiva que ocorre no município a fim de avaliar a percepção ambiental dos munícipes. Assim, de acordo com os questionários, pode-se perceber que a população se apresenta conscientizada quanto à segregação dos resíduos recicláveis e a frequência de coleta dos mesmos. Sendo que, 93,38\% das residências urbanas no município realizam a segregação dos resíduos e 83,46\% conhece a frequência da coleta seletiva. Quanto à coleta convencional de resíduos, apenas $13,42 \%$ dos entrevistados afirmaram ter conhecimento da frequência de coleta.

Entretanto, de acordo com a composição gravimétrica obtida no quarteamento, 45,79\% dos resíduos destinados a disposição final, no aterro sanitário municipal, foram classificados como recicláveis. Além disso, durante o quarteamento, constatou-se a presença de resíduos segregados pela população sendo destinados ao aterro, indicando a intenção do encaminhamento destes a associação de catadores, gerando assim uma 
maior exaustão da capacidade do aterro. Assim, pode-se inferir que a população desconhece o cronograma da coleta convencional e seletiva ou este coincide com o da coleta convencional de resíduos sólidos. Demonstrando com isso, uma falha no gerenciamento de resíduos quanto à organização e divulgação dos cronogramas de coleta.

Grande parte dos resíduos recicláveis dispostos no aterro sanitário não se apresentava discriminados pela população. Esta constatação mostra que embora a população afirmasse realizar a segregação dos resíduos, as ações identificadas mostram que ainda existe uma grande resistência à mudança de postura, a favor da reciclagem. Quando questionados sobre a destinação final dos resíduos sólidos os entrevistados podiam escolher até duas opções, sendo estas: Aterro Sanitário, Lixão, Associação de Catadores ou; Não Sabe. De maneira geral, $66,36 \%$ dos entrevistados afirmaram não conhecer a destinação final dada aos RSU no município, $21,88 \%$ indicaram o Aterro Sanitário, $11,81 \%$, Lixão. Sobre os lixões vale salientar que esta solução foi o destino de grande parte do lixo coletado pelos municípios brasileiros durante muito tempo (GONÇALVES, 2005).

Considerando-se a porcentagem dos entrevistados por bairro que responderam não saber a destinação final dos resíduos sólidos domiciliares, ou que indicaram o lixão, tem-se a Figura 11. Observa-se assim que, a maioria da população desconhece a disposição final de resíduos no Município, que ocorre no aterro sanitário municipal, sendo que, o bairro Jardim Primavera foi o que apresentou maior grau de desconhecimento, $93,48 \%$ dos entrevistados.

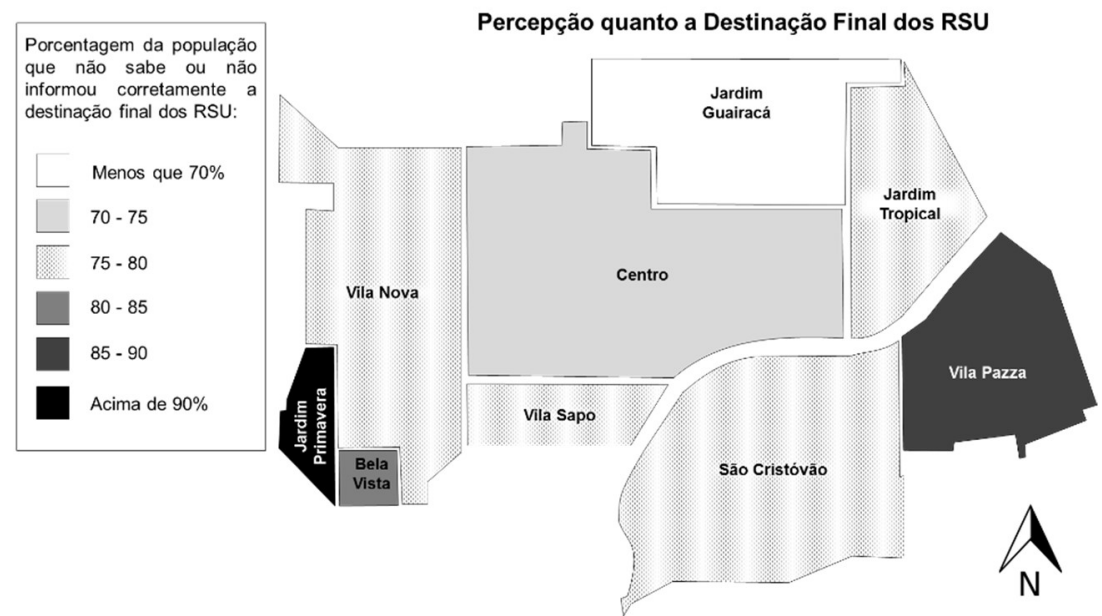

Figura 11: Distribuição espacial da percepção por bairros, quanto à disposição final.

Segundo Mucelin et al. (2008) para as populações urbanas a principal operação do gerenciamento de resíduos sólidos restringe-se a coleta. Sendo que, a mesma deve ocorrer de forma eficiente, minimizandose impactos visuais e proliferação de vetores, visto que estes ocorrem próximos da população, assim, o resultado obtido mostra o desinteresse da população pela disposição final adotada no município. A partir desses pressupostos, pode-se afirmar que para tratar o problema dos resíduos sólidos urbanos é preciso que a população desenvolva um autoconhecimento. Isto é, que saibam o processo de formação, coleta, tratamento e disposição final dos resíduos sólidos, e que este conhecer seja incorporado às ações (OLIVEIRA, 2006). 
Com base nos resultados obtidos, pode-se inferir que o bairro Jardim Primavera apresentou resultados inferiores, se comparado com os outros bairros, quanto à renda familiar e a percepção da população quanto à disposição final de resíduos sólidos urbanos adotada pelo Município, mostrando desta forma uma possível relação entre o fator econômico e a percepção ambiental. Quanto ao bairro Centro, os entrevistados indicaram possuir um nível de escolaridade elevada, e posição econômica privilegiada além de apresentar maior conhecimento relativo à disposição final adotada pela gestão municipal.

Logo, esse fato ressalta a hipótese que o grau de escolaridade, bem como a renda, pode ser fatores determinantes que influenciam na concepção e sensibilização dos indivíduos referentes aos serviços de gerenciamento dos resíduos sólidos. Porém, para afirmação de tal acontecimento, exige um estudo mais aprofundado e detalhado. Um outro fato interessante, descoberto durante as entrevistas, foi o relato dos munícipes referente ao costume de usar os restos de resíduos orgânicos como adubo em hortas caseiras e alimentação dos animais.

\section{Diretrizes para o gerenciamento}

As proposições das diretrizes tornam-se um excelente instrumento de auxílio para o gestor público, visto o embasamento proporcionado pelo diagnóstico. No Quadro 1 apresenta-se uma síntese das diretrizes recomendadas para a regularização das condições de gerenciamento dos RSU no município de Matelândia, visando a eficiência e minimização dos impactos ambientais gerados por essa atividade.

Quadro 1: Proposição de Diretrizes para o gerenciamento dos RSU em Matelândia.

\begin{tabular}{|c|c|c|}
\hline Objetivo & Situação atual & Ações \\
\hline \multirow{3}{*}{$\begin{array}{l}\text { Regularizar o } \\
\text { cronograma da coleta } \\
\text { convencional e seletiva }\end{array}$} & \multirow{3}{*}{$\begin{array}{l}\text { Aproximadamente } 46 \% \text { dos resíduos dispostos no } \\
\text { aterro sanitário municipal são recicláveis, } \\
\text { implicando na redução da renda dos associados e } \\
\text { reduzindo a vida útil do aterro. }\end{array}$} & $\begin{array}{l}\text { Reestruturar e colocar em prática os cronogramas } \\
\text { da coleta convencional e seletiva. }\end{array}$ \\
\hline & & $\begin{array}{l}\text { Divulgar os novos cronogramas de coleta para os } \\
\text { munícipes. }\end{array}$ \\
\hline & & $\begin{array}{l}\text { Estabelecer um programa de Educação Ambiental } \\
\text { para a sensibilização dos munícipes e comércios de } \\
\text { pequeno porte sobre a importância de separar os } \\
\text { seus resíduos gerados. }\end{array}$ \\
\hline \multirow{2}{*}{$\begin{array}{l}\text { Adequar à } \\
\text { infraestrutura } \\
\text { operacional do Aterro } \\
\text { Sanitário }\end{array}$} & \multirow[t]{2}{*}{$\begin{array}{l}\text { Falta de equipamentos e máquinas necessários } \\
\text { para adequada operação do Aterro Sanitário }\end{array}$} & Instalar uma balança na entrada do aterro. \\
\hline & & Adquirir uma pá carregadeira e trator esteira. \\
\hline \multirow{2}{*}{$\begin{array}{l}\text { Adequar à operação do } \\
\text { Aterro Sanitário }\end{array}$} & $\begin{array}{l}\text { Falta de conhecimento sobre as técnicas de manejo } \\
\text { de RSU promovendo queda na eficiência do } \\
\text { funcionamento do mesmo. }\end{array}$ & $\begin{array}{l}\text { Treinamento e capacitação dos responsáveis e } \\
\text { funcionários. }\end{array}$ \\
\hline & Não ocorre o monitoramento hídrico e geotécnico & $\begin{array}{l}\text { Instalar e identificar os pontos de monitoramento (à } \\
\text { montante e jusante do aterro) e Contratar uma } \\
\text { empresa terceirizada para realizar } \\
\text { monitoramento da água e geotécnico. }\end{array}$ \\
\hline \multirow{3}{*}{$\begin{array}{l}\text { Melhorar as condições } \\
\text { de trabalho dos } \\
\text { associados }\end{array}$} & A inexistência de um local próprio & $\begin{array}{l}\text { Reformar o prédio/galpão da ASCARMAT com } \\
\text { impermeabilização do piso e espaço suficiente para } \\
\text { recepção, triagem e armazenamento temporário } \\
\text { dos rejeitos. }\end{array}$ \\
\hline & Condições precárias de operação & $\begin{array}{l}\text { Adequar a estrutura operacional do sistema de } \\
\text { triagem, elevação de cargas e baias de } \\
\text { armazenamento. }\end{array}$ \\
\hline & Condições inadequadas de higiene e segurança & $\begin{array}{l}\text { Elaborar, executar e fiscalizar a execução de um } \\
\text { PPRA (Programa de Prevenção de Riscos } \\
\text { Ambientais) por profissional adequado. }\end{array}$ \\
\hline
\end{tabular}




\section{CONCLUSÕES}

Esforços vêm sendo aplicados na elaboração das políticas públicas que tem a finalidade de melhorar a gestão dos resíduos sólidos no Brasil, porém, os municípios de pequeno porte apresentam dificuldades na execução, seja por fatores financeiros ou por falta recursos humanos capacitados. Conhecer os pontos a serem melhorados é o primeiro passo para solucionar essa questão, por isso a relevância da elaboração de estudos de diagnósticos.

O levantamento de informações sobre o gerenciamento dos RSU fornece ao gestor não apenas o volume de resíduos gerados no município, mas um panorama do manejo destes, desde a geração até a destinação final (aterro e associação de reciclagem). A partir dos aspectos levantados, sejam estes positivos ou negativos, o gestor tem suporte para realizar o planejamento de ações corretivas e/ou preventivas. Em Matelândia/PR, observou-se como a falta de infraestrutura influencia no gerenciamento dos RSU, além de evidenciar a falta de preparação técnica dos colaboradores envolvidos.

A geração per capita e o peso específico dos resíduos foram, respectivamente, 0,334 kg.hab ${ }^{-1} \mathrm{dia}^{-1} \mathrm{e}$ $128 \mathrm{~kg} \mathrm{~m}^{-3}$. Valores estes, inferiores à média nacional. Uma possível justificativa para este resultado é o fato que alguns munícipes possuírem o hábito de usar os resíduos orgânicos em hortas e alimentação de animais, conforme foi constado no momento das entrevistas, podendo interferir nesses valores.

O índice de qualidade de operação e funcionamento do aterro sanitário municipal permitiu inferir que a infraestrutura instalada no local não vem sendo utilizada de forma correta, reduzindo assim a vida útil planejada para a área. Quanto à ASCARMAT, as inadequadas condições de operação refletem no volume de resíduos recicláveis comercializados e a deficiência de higiene e segurança representa uma situação de risco aos associados, gerando assim uma evasão dos trabalhadores do local.

As diretrizes propostas dependem de investimento inicial e possuem um custo operacional contínuo por parte da gestão pública. Entretanto a adequação no gerenciamento dos RSU promove diversos benefícios a curto, médio e longo prazo, inclusive economia de recursos futuros. Todas as diretrizes propostas, de maneira geral promovem o aumento da vida útil do aterro sanitário municipal, se comparado com o cenário atual, economizando assim recursos com a seleção de uma nova área e implantação de um novo aterro no futuro e, até mesmo, multas ambientais.

\section{REFERÊNCIAS}

ABRAMOVAY, R.; SPERANZA, J. S.; PETITGAND, C.. Lixo Zero: Gestão de resíduos sólidos para uma sociedade mais próspera. São Paulo: Planeta Sustentável: Instituto Ethos, 2013.

ABREPLE. Associação Brasileira de Empresas de Limpeza Pública e Resíduos Especiais. Panorama dos Resíduos Sólidos no Brasil 2016. 14 ed. 2015.

BARRETO, E. V.; MELO, E. S. R. L.; ALCÂNTARA, G. F.; PAIVA, V.. Análise de composição de resíduos sólidos urbanos como instrumento de gestão em política pública de saneamento. In: CONGRESSO BRASILEIRO DE GESTÃO AMBIENTAL, 5.

Anais. Porto Alegre, 2015.
ABNT. Associação Brasileira de Normas Técnicas. NBR 10007: Estabelece requisitos exigíveis para amostragem de resíduos sólidos. $2004 b$.

BRASIL. Ministério das Cidades. Plano diretor participativo: guia para a elaboração pelos municípios e cidadãos. 2 ed. Brasília: Confea, 2005.

BRASIL, Ministério do Meio Ambiente. Gerência de Resíduos Sólidos. Orientações para elaboração de Plano Simplificado de Gestão Integrada de Resíduos Sólidos - PSGIRS para municípios com população inferior a $\mathbf{2 0}$ mil habitantes: manual de orientação. Brasília: MMA, 2013. 
BRASIL. Ministério do Meio Ambiente. Plano Nacional de Resíduos Sólidos. Brasília: MMA, 2012.

CAMPOS, H. K. T.. Renda e evolução per capita de resíduos sólidos no Brasil. Revista Engenharia Sanitária Ambiental, Rio de Janeiro, v.17, n.2, p.171-180, 2012.

CETESB. Companhia Ambiental do Estado de São Paulo. Inventário Estadual de Resíduos Sólidos Domiciliares. São Paulo, 2010.

COSTA, L. E. B.; COSTA, L. E. B.; COSTA, S. K.; REGO, N. A. C.; SILVA JÚNIOR, M. F.. Gravimétrica dos resíduos sólidos urbanos domiciliares e perfil socioeconômico no município de Salina, Minas Gerais. Revista Ibero-Americana de Ciências Ambientais, Aquidabã, v.3, n.2, p.73-900, 2012. DOI: $\underline{\text { http://10.6008/ESS2179-6858.2012.002.0005 }}$

COSTA, C. C.. Percepção ambiental dos policiais do pelotão de polícia militar ambiental do estado de Sergipe, Revista Ibero-Americana de Ciências Ambientais, Aquidabã, v.4, n.1, p.15-32, 2013. DOI: http://10.6008/ESS21796858.2013 .001 .0002

CRUZ, J. V.; VIEIRA, W.; LIMA, L. R.; SOTO, F. R. M.. Diagnóstico de gerenciamento de resíduos sólidos domiciliares na estância turística de Ibiúna (SP) Brasil. Revista Ibero-Americana de Ciências Ambientais, Aquidabã, v.6, n.2, p.246-257, 2015. DOI: http://10.6008/SPC2179$\underline{6858.2015 .002 .0017}$
GIL, A. C.. Métodos e técnicas de pesquisa social. 6 ed. São Paulo: Atlas, 2008.

GONÇALVES, R. C. M.. A voz dos catadores de lixo em sua luta pela sobrevivência. Tese (Mestrado em Políticas Públicas) - Universidade Estadual do Ceará, Fortaleza, 2005.

IPARDES. Instituo Paranaense de Desenvolvimento Econômico e Social. Caderno Estatístico do Município de Matelândia. 2015.

MINISTÉRIO DAS CIDADES. Secretaria Nacional de Saneamento Ambiental. Sistema Nacional de Informações sobre Saneamento. Diagnóstico do Manejo de Resíduos Sólidos Urbanos - 2015. Brasília, 2017.

MUCELIN, C. A.; BELLINI, M.. Lixo e impactos ambientais perceptíveis no ecossistema urbano. Sociedade \& Natureza, Uberlândia, v.20, n.1, 2008.

OLIVEIRA, N. A. S.. A Percepção dos Resíduos Sólidos (lixo) de origem domiciliar, no bairro Cajuru - Curitiba/PR: um olhar reflexivo a partir da educação ambiental. Tese (Mestrado em Geografia- Ciências da Terra) - Universidade Federal do Paraná, Curitiba, 2006.

VIEIRA, M. L.; LACERDA, A. L. R.; VIEIRA, M.; MOURA, M. L.. Características sociodemográficas e aspectos psicossociais de famílias brasileiras residentes em capitais e cidades pequenas do interior. Revista do Departamento de Ciências Humanas, Santa Cruz do Sul: Barbarói, n.34, 2011.

A CBPC - Companhia Brasileira de Produção Científica (CNPJ: 11.221.422/0001-03) detém os direitos materiais desta publicação. Os direitos referem-se à publicação do trabalho em qualquer parte do mundo, incluindo os direitos às renovações, expansões e disseminações da contribuição, bem como outros direitos subsidiários. Todos os trabalhos publicados eletronicamente poderão posteriormente ser publicados em coletâneas impressas sob coordenação da Sustenere Publishing, da Companhia Brasileira de Produção Científica e seus parceiros autorizados. Os (as) autores (as) preservam os direitos autorais, mas não têm permissão para a publicação da contribuição em outro meio, impresso ou digital, em português ou em traduçãoo. 